\title{
ANÁliSE ESTRUTURAL DA CEBOLA NO BRASIL: PERÍODO DE 1995 A 2007
}

\author{
SILVA, Danilo Teodoro Mattos ${ }^{1}$ \\ BRUNINI, Maria Amalia ${ }^{2}$ \\ KANESIRO, Lidiane Aparecida ${ }^{3}$
}

\section{Recebido em: 2009.10 .28}

Aprovado em: 2009.12.05

ISSUE DOI: $10.3738 / 1982.2278-301$

\begin{abstract}
RESUMO: Este estudo apresenta o perfil da área cultivada, produção, produtividade e a evolução da importação de cebola no Brasil, durante o período de 1995 a 2007. Através dos dados analisados pode-se verificar que, apesar da área cultivada ter diminuído em várias regiões brasileiras, a produção aumentou devido, principalmente, ao uso de cultivares mais produtivos; que o maior estado brasileiro produtor é o de Santa Catarina; e que a quantidade de cebola importada diminuiu neste período em virtude de safra brasileira coincidir com a safra de outros países. Pode-se concluir que o mercado brasileiro deve disponibilizar cultivares adaptável a cada região de geográfica e investir mais em tecnologias, para que as regiões geográficas tenham estabilidade de produção.
\end{abstract}

Palavras-chave: Allium cepa, L. Produção. Produtividade. Área cultivada. Importação.

\section{STRUCTURAL ANALYSE OF ONION IN THE BRAZIL: FROM 1995 TO 2007}

SUMMARY: This study presents the profile of the cultivated area, production, productivity and the evolution of the import anion in the Brazil, during the period from 1995 to 2007. Through the analyzed data it can be verified that, in spite of the cultivated area to have decreased in several Brazilian areas, the production increased, due, mainly, to the use of you cultivate more productive; that the largest producing Brazilian state is of Santa Catarina; and that the amount of imported onion decreased in this period because of Brazilian harvest to coincide with the harvest of other countries. It can be concluded that the Brazilian market should make available cultivate adaptable to each area of geographical and to invest more in technologies, to that the geographical areas have production stability.

Keywords: Allium cepa L. Production. Productivity. Cultivated área

\section{INTRODUÇÃO}

$\mathrm{Na}$ horticultura brasileira, a cebola (Allium cepa $L$ ) é considerada a terceira hortaliça de maior importância econômica, apresentando significativo aumento de produção nos últimos anos (REZENDE et al., 2002), perdendo apenas para o tomate e batata (CARDOSO;

\footnotetext{
${ }^{1}$ Engenheiro Agrônomo e acadêmico do Curso de Pós-graduação Lato sensu Agronegócio e Desenvolvimento Sustentável da Faculdade Dr. Francisco Maeda/FE. Rodovia Jeronimo Nunes Macedo, Km 01, Ituverava/SP. $\mathrm{CEP}=14500-000$. E-mail: danilotteodoro@ hotmail.com

${ }^{2}$ Professora Doutora Adjunto Aposentada da Faculdade de Ciências Agrárias e Veterinárias, Campus de Jaboticabal/UNESP e Doutora da Fundação Educacional de Ituverava/FE. Rodovia Jerônimo Nunes Macedo, Km 01, Ituverava/SP. CEP=14500-000. E-mail: amaliabrunini@ @etsite.com.br ou brunini@ feituverava.com.br

${ }^{3}$ Professora Mestre do Programa de Pós-graduação daFaculdade Dr. Francisco Maeda/FE e Professora Mestre da Faculdade de Filosofia Ciências e Letras de Ituverava. Rodovia Jerônimo Nunes Macedo, Km 01, Ituverava/SP. CEP=14500-000. E-mail: lidy@ netsite.com.br
} 
COSTA, 1999). Segundo Souza e Rezende (2002), é a cultura mais importante sob o ponto de vista de consumo, pois pode ser consumida na forma in natura, em saladas, temperos e condimentos. O aumento no consumo de cebola é pela sua capacidade de adicionar sabor a outros alimentos e por estar associado.

Quanto ao abastecimento no Brasil, pode-se verificar que sofreu e está sofrendo alterações devido o fornecimento de cebola argentina, entre outros fatores (CAMARGO FILHO; ALVES, 2005). Camargo Filho e Mazzei (2001) citam que a cebola é a hortaliça que apresenta maior oscilação de preço pelas suas características intrínsecas na cadeia produtiva, e por ser uma cultura tipicamente familiar, e segundo Souza e Resende (2002), a maioria da produção de cebola é conduzida no sistema convencional, ou seja, com o uso de fertilizantes e defensivos químicos.

Como a produção de cebola interfere significativamente no mercado brasileiro de hortaliças, a realização deste estudo sobre produção e mercado é de suma importância para subsídios de políticas setoriais e planejamento estratégico de produção e comercialização.

Dessa forma, o objetivo desse trabalho foi o de mostrar a evolução de produção, área plantada, produtividade e importação de cebola no Brasil, durante o período de 1995 a 2007.

\section{METODOLOGIA}

Para a realização desse estudo foram utilizados dados de produção, produtividade, área cultivada e importação de cebola no Brasil publicada em Censos Agropecuários, Anuários Estatísticos, AGRIANUAL, Instituto de Economia Agrícola e IBGE. Adicionalmente foram utilizadas informações obtidas em relatórios de encontros técnicos e de outros trabalhos.

Os resultados foram descritos com base na análise das informações a partir dos dados obtidos, que foram codificados, digitados em planilha eletrônica, em forma de banco de dados (Excel for Windows), distribuídos em gráficos e analisados qualitativamente e quantitativamente.

\section{RESULTADOS E DISCUSSÃO}

A cultura da cebola é uma das hortaliças mais cultivada, a qual segundo Vilela et al. (2002) apud Vilela et al. (2005), tem caráter familiar e é responsável pela viabilização de pequenas propriedades e na fixação de pequenos produtores na zona rural.

No Brasil como um todo, analisando o período de 1995 a 2007, a produção brasileira de cebola avançou de 940,53t para 1.225,154t ( AGRIANUAL 1999/2002/2005/2008, IBGE 
$2008 \mathrm{a} / \mathrm{b}$ ), embora a área cultivada tenha diminuído de 74.676 ha para 58.909 ha (Tabela 1). Esse aumento na produção permite afirmar que o avanço decorreu de progresso técnico, principalmente, pela introdução de novas variedades que apresentam maior produtividade (toneladas por hectare), fato este que pode ser verificado pelos dados da Tabela 1, onde se observa aumento na produtividade da ordem de 63,19\% durante o período de 1995 a 2007 (de 12,59 t.ha' ${ }^{-1}$ para 20,79 t.ha $\left.{ }^{-1}\right)$.

Tabela 1: Área cultivada e produção de cebola no Brasil, durante o período de 1995 a 2007.

\begin{tabular}{c|c|c|c}
\hline Ano Agrícola & $\begin{array}{c}\text { Área cultivada (em } \\
\text { hectare) }\end{array}$ & $\begin{array}{c}\text { Produção (em } \\
\text { toneladas) }\end{array}$ & $\begin{array}{c}\text { Produtividade( em } \\
\text { t.ha }^{-1} \text { ) }\end{array}$ \\
\hline 1995 & 74.676 & 940.537 & 12,59 \\
\hline 1996 & 69.838 & 897.643 & 12,85 \\
\hline 1997 & 67.801 & 881.134 & 12,99 \\
\hline 1998 & 67.745 & 838.232 & 12,37 \\
\hline 1999 & 66.169 & 990.093 & 14,94 \\
\hline 2000 & 66.505 & 1.156 .332 & 17,38 \\
\hline 2001 & 63.931 & 1.050 .360 & 16,42 \\
\hline 2002 & 68.869 & 1.222 .124 & 17,74 \\
\hline 2003 & 68.790 & 1.229 .848 & 17,87 \\
\hline 2004 & 58.361 & 1.157 .562 & 19,83 \\
\hline 2005 & 56.388 & 1.137 .684 & 19,48 \\
\hline 2006 & 57.209 & 1.174 .746 & 20,53 \\
\hline 2007 & 58.909 & 1.225 .154 & 20,79 \\
\hline
\end{tabular}

Fonte: AGRIANUAL (1999/2002/2005/2008/2009) e IBGE (2008 a/b).

Em termos de produtividade, através dos dados levantados no AGRIANUAL (1999/2002/2005/2008/2009), o aumento verificado (Figura 1) pode ser justificado pela citação de Vilela et al. (2005) de que a cadeia produtiva da cebola apresenta cenários distintos tanto na cadeia de produção como na da escolha de cultivares. Ainda, segundo estes mesmos autores, no segmento da produção a preocupação com a competição externa colocou o atendimento às exigências de mercado como o principal centro de atenções do agronegócio da cebola, levando os produtores a optarem por cultivares com maior produtividade e resistência a doenças e pragas, mas também com alto padrão de qualidade. 


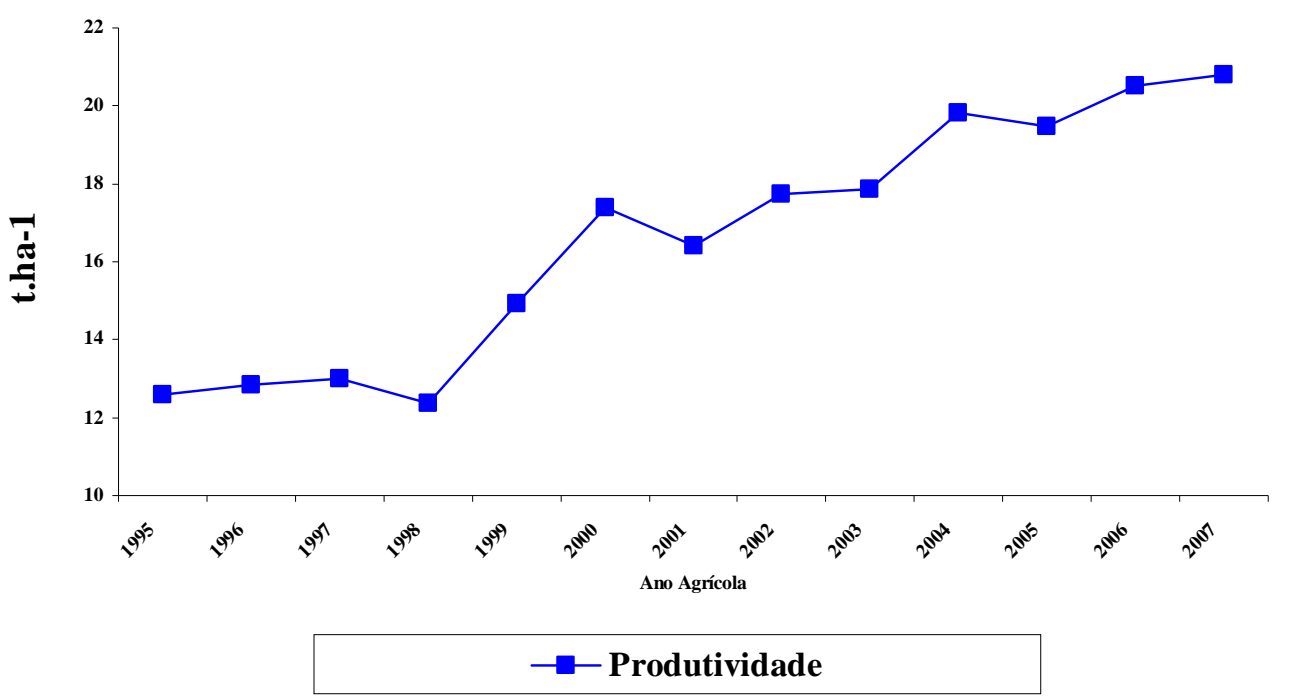

Figura 1: Produtividade da cultura da cebola no Brasil, em t.ha ${ }^{-1}$, durante o período de 1995 a 2007.

Quanto à área colhida, através de dados levantados junto ao AGRIANUAL (1999/2002/2005/2008/2009), pode-se verificar pela Figura 2 que a mesma oscilou durante o período de 1995 a 2007, nas diferentes regiões geográficas do Brasil, e que a partir de 2004 diminuiu, acentuadamente, nas regiões Sudeste e aumentou na região Nordeste.
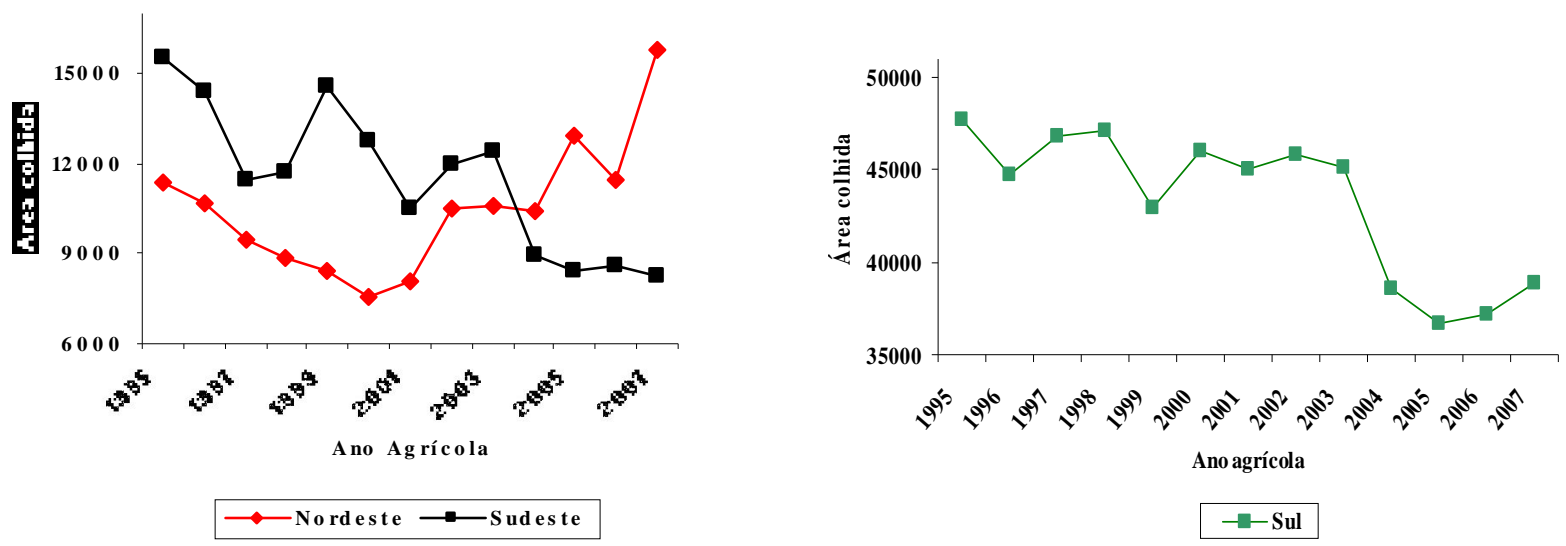

Figura 2: Área colhida de cebola, em hectare, por região geográfica brasileira, de 1995 a 2007.

Quanto à produção de cebola por região geográfica pode-se verificar que aumentou na região Nordeste de 156.321t para 259.810t, na região Sul de 448.961t para 702.474t, enquanto que na região Sudeste diminuiu de 333.813t para 262.870t (Tabela 2). Pode-se verificar pelos dados levantados que, na região Centro Oeste, a produção é muito oscilante, pois no período de 1997 a 1998 e de 2006 a 2007 não houve produção. 
Tabela 2: Produção de cebola em toneladas, por região geográfica brasileira, durante o período de 19952007.

\begin{tabular}{c|c|c|c|c}
\hline \multirow{2}{*}{ Ano Agrícola } & \multicolumn{4}{|c}{ Regiões geográficas brasileiras } \\
\cline { 2 - 5 } & Nordeste & Sudeste & Sul & CentroOeste \\
\hline 1995 & 156.321 & 333.813 & 448.961 & 1.442 \\
\hline 1996 & 144.203 & 312.212 & 438.100 & 3.128 \\
\hline 1997 & 138.180 & 264.810 & 480.998 & ---- \\
\hline 1998 & 116.774 & 220.562 & 489.937 & ---- \\
\hline 1999 & 118.462 & 289.254 & 582.377 & ---- \\
\hline 2000 & 123.337 & 328.428 & 697.318 & 7.249 \\
\hline 2001 & 170.203 & 284.100 & 620.638 & 11.419 \\
\hline 2002 & 233.957 & 342.949 & 630.282 & 24.936 \\
\hline 2003 & 242.316 & 349.078 & 609.240 & 29.214 \\
\hline 2004 & 205.992 & 255.317 & 675.017 & 21.236 \\
\hline 2005 & 273.627 & 269.024 & 577.297 & 17.736 \\
\hline 2006 & 251.966 & 277.040 & 645.740 & ---- \\
\hline 2007 & 259.810 & 262.870 & 702.474 & ---- \\
\hline
\end{tabular}

FONTE: AGRIANUAL (1999/2002/2005/2008/2009).

Dentre as principais unidades da Federação, os estados maiores produtores de cebola são Santa Catarina, que de 1995 a 2007 a produção aumentou de 258.238t para 436.502t, Rio Grande do Sul, onde a produção de 138.302t para 161.559t e o estado de São Paulo(Tabela 3). O estado de São Paulo apesar de a produção ter diminuído de 320.080t para 197.620t, continua sendo um dos estados de maior produção nacional de cebola.

Tabela 3: Produção de cebola, em toneladas, nas regiões Sudeste e Sul do Brasil, durante o período de 1995 a 2007.

\begin{tabular}{c|c|c|c|c|c|c}
\hline \multirow{2}{*}{$\begin{array}{c}\text { Ano } \\
\text { Agrícola }\end{array}$} & \multicolumn{3}{|c|}{ Região Sudeste } & \multicolumn{3}{c}{ Região Sul } \\
\cline { 2 - 7 } & MG & ES & SP & PR & SC & RS \\
\hline 1995 & 13.462 & 271 & 320.080 & 52.421 & 258.238 & 138.302 \\
\hline 1996 & 30.287 & 315 & 281.610 & 59.555 & 226.445 & 152.100 \\
\hline 1997 & 16.893 & 315 & 245.290 & 57.237 & 259.755 & 162.250 \\
\hline 1998 & 19.402 & 312 & 200.740 & 56.239 & 272.700 & 166.147 \\
\hline 1999 & 43.834 & & 245.420 & 56.400 & 348.630 & 177.347 \\
\hline 2000 & 55.556 & & 272.560 & 52.800 & 456.036 & 181.621 \\
\hline 2001 & 64.280 & 1.200 & 182.620 & 65.858 & 375.551 & 179.229 \\
\hline 2002 & 70.819 & 1.200 & 270.930 & 73.356 & 394.582 & 162.344 \\
\hline 2003 & 79.683 & 2.500 & 266.895 & 76.362 & 409.553 & 123.325 \\
\hline 2004 & 66.122 & 3.075 & 186.120 & 80.326 & 436.597 & 158.094 \\
\hline 2005 & 67.981 & 4.792 & 196.251 & 88.009 & 353.077 & 136.211 \\
\hline 2006 & 79.420 & & 197.620 & 103.976 & 395.439 & 146.325 \\
\hline 2007 & 68.347 & & 193.267 & 114.151 & 436.502 & 161.559 \\
\hline
\end{tabular}

FONTE: AGRIANUAL (1999/2002/2005/2008/2009) 
Quanto à produção de cebola nas regiões geográficas Nordeste e Centro Oeste, podeser verificado pelos dados da Tabela 4 que os estados da região Centro-Oeste contribuem com muito pouco na produção nacional, enquanto que a região Nordeste contribui com uma grande parcela. Dentre as unidades federativas da região Nordeste, o estado da Bahia se sobressai, pois a produção que em 1995 era de 75.375t aumentou para 239.736t em 2007, aumento este de $218,06 \%$.

A oscilação observada na produção por estado brasileiro revela existência da falta do elemento típico de cadeia de comercialização nestas regiões (sistemas produtivos, fornecedores de insumos e serviços, industriais de processamento e transformação, agentes de distribuição e comercialização, além de consumidores finais), e de estruturas agroindustriais para absorção de excedente de produção.

Tabela 4: Produção de cebola, em toneladas, nas regiões Nordeste e Centro Oeste do Brasil, durante o período de 1995 a 2007.

\begin{tabular}{c|c|c|c|c|c|c|c|c|c}
\hline \multirow{2}{*}{$\begin{array}{c}\text { Ano } \\
\text { Agrícola }\end{array}$} & \multicolumn{7}{|c|}{ Região Nordeste } & \multicolumn{3}{|c}{ Região Centro Oeste } \\
\cline { 2 - 10 } & PI & CE & RN & PB & PE & BA & MS & GO & DF \\
\hline 1995 & 255 & 12 & & 560 & 80.080 & 75.375 & & & 1.442 \\
\hline 1996 & 189 & 14 & & 76 & 68.567 & 75.314 & & & 3.128 \\
\hline 1997 & 150 & 1 & & 310 & 76.710 & 61.560 & 120 & 126 & 357 \\
\hline 1998 & 60 & 8 & & 517 & 55.000 & 66.487 & 88 & & 480 \\
\hline 1999 & & & & & 62.351 & 56.069 & & & \\
\hline 2000 & & & & & 48.573 & 74.667 & & & \\
\hline 2001 & 38 & 6 & & 30 & 68.834 & 101.295 & 81 & 5.980 & 5.358 \\
\hline 2002 & 62 & & & 90 & 89.082 & 134.723 & 142 & 19.430 & 5.364 \\
\hline 2003 & 35 & & & 92 & 91.353 & 150.836 & 159 & 20.710 & 8.345 \\
\hline 2004 & 30 & & & 233 & 74.205 & 131.524 & & 17.100 & 4.136 \\
\hline 2005 & 30 & & 1120 & 143 & 98.776 & 173.558 & & 13.650 & 4.086 \\
\hline 2006 & & & & & 98.957 & 153.009 & & & \\
\hline 2007 & & & & & 98.458 & 239.736 & & & \\
\hline
\end{tabular}

FONTE: AGRIANUAL (1995/2002/2005/2008/2009)

\section{MERCADO BRASILEIRO}

O Brasil é o um dos maiores importadores de cebola, principalmente da cebola argentina, o que pode ser atribuído ao bom aspecto e conservação da mesma. De acordo com Camargo Filho (1999) os brasileiros ao optarem pelo produto importado estão agregando valor a outro país. Outro fator que leva o Brasil a ser um dos principais países importadores de cebola é a abertura de mercados consolidados nos anos 90 pelo MERCOSUL, que provocaram mudanças na estrutura e comercialização da cebola (CAMARGO et al., 2006). 
Através de dados levantados junto ao AGRIANUAL (1999 a 2009) pode-se verificar que em 1996 o Brasil importou 250.943t e em 2007 importou 157.153t (Figura 3), o que representa uma queda de 37,38\%. Esta queda pode ser explicada pela implantação de um planejamento de produção com cultivares mais produtivos, e pela produção em alguns estados brasileiros coincidirem com a cebola comercializada por outros países.

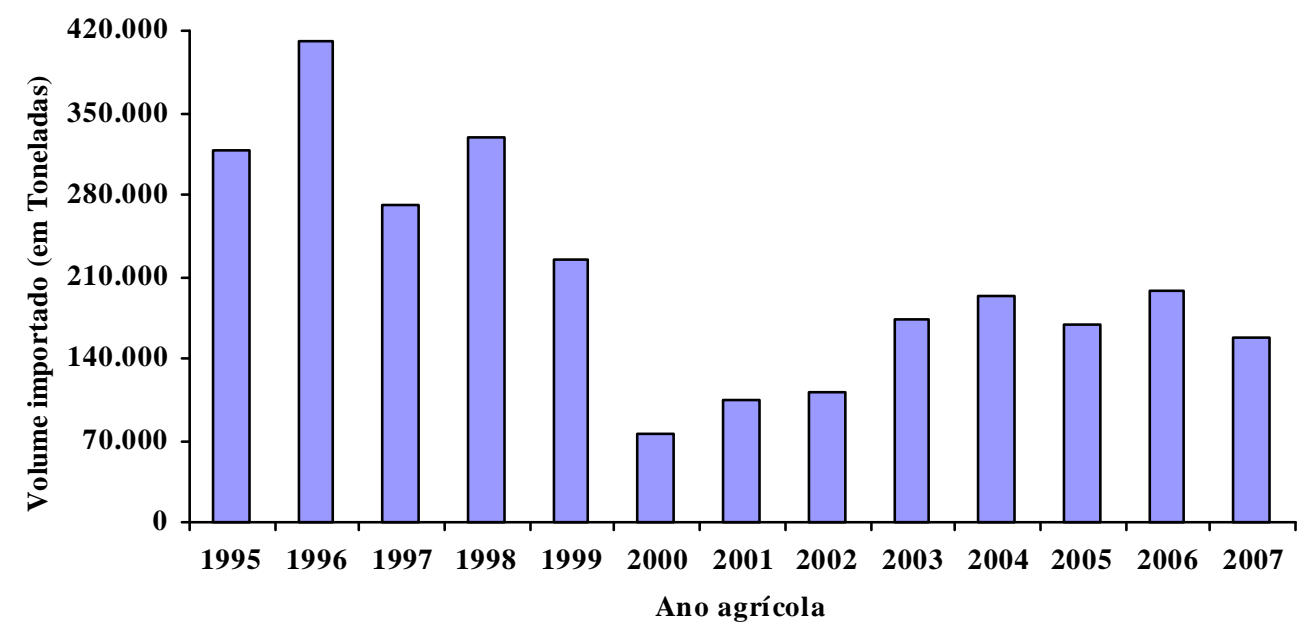

Figura 3: Importações brasileiras de cebola, em toneladas, durante o período de 1995 a 2007.

Outro fator que pode ter contribuído para a diminuição da importação da cebola é que ocorreu aumento no processamento da cebola brasileira em pasta de alho e cebola desidratada, disponibilizando-a por maior período aos consumidores brasileiros.

Segundo dados do IBGE (2008), apesar do consumo de bulbos de cebola ter diminuído de $6,5 \mathrm{~kg}$ por habitante por ano para $3,5 \mathrm{~kg}$ por habitante por ano, o consumo de derivados aumentou, e de acordo com Camargo Filho et al (1993) apud Resende et al. (2007) o consumo anual per capita de cebola está em torno de 6,54 hg. Vale aqui ressaltar que o consumo pesquisado pelo IBGE não levou em consideração o consumo institucional. Segundo Resende et al. (2007), o consumo total de cebola em bulbo no Brasil nos últimos anos está, praticamente, estabilizado entre 750 mil a 850 mil toneladas por ano.

Um dos fatores que leva o Brasil a ser um dos países que mais importa cebola, junto com outros países como Estados Unidos, Alemanha, Rússia e Japão é que a cebolicultura, para a maior parte dos produtores, ser a única fonte de renda, precisando portanto ser comercializada logo após a colheita. Segundo Vilela et al. (2002) apud Vilela et al. (2005), além de a cebola ser a única fonte de renda da maioria dos produtores, a sua rápida comercialização coloca no mercado produtos mal curados que ficam suscetíveis a deteriorização e ao apodrecimento por falta de redes adequadas de armazenamento. Ainda, 
segundo estes mesmos autores, esta situação traz queda nos preços e eleva os níveis de perda de produção.

Outros fatores que interferem na importação de cebola é a oscilação de preços devido ao grande número de regiões produtoras, pois a maioria não possui cultivar específico e estabilidade de período de produção, o que leva a irregularidade no abastecimento interno, e o acordo dentro do MERCOSUL, entre o Brasil e Argentina, onde, segundo Vilela et al. (2005) foi planejado um espaço de 150 mil t, no mercado brasileiro, para a produção argentina.

\section{CONSIDERAÇÕES FINAIS}

Pelos dados apresentados nesse estudo e pela análise dos mesmos, pode-se verificar que a produção nacional de cebola por unidade da Federação apresentou oscilação entre os anos de 1995 a 2007, apesar do aumento da produtividade (t.ha ${ }^{-1}$ ), que levou a instabilidade de abastecimento no mercado interno, tornando o Brasil um dos países que mais importa cebola em bulbo. Apesar da importação, de 1996 a 2007, ter diminuído em 37,38\%, o Brasil é considerado o $7^{\circ}$ país no ranking de importação, e dentre os países de origem de importação, o Brasil, do total importado, importa 99,60\% da Argentina.

Outro fator que contribui para a importação de cebola argentina pelo Brasil é a procura pelo consumidor, pois esta cebola apresenta boa aparência associada à conservação póscolheita, além do acordo MERCOSUL.

Para que o Brasil consiga reverter a preferência e o consumo de cebola argentina pelos seus cidadãos, os produtores terão que, além de aumentar a produtividade, diferenciar os produtos em qualidade, aspecto e conservação pós-colheita. Além disto, há necessidade de uma mudança significativa na distribuição regional da cultura e nas redes de distribuição, seja no contexto nacional, estadual e regional, bem como as agroindústrias assumirem papel relevante, tanto para absorverem os excedentes de produção como para agregar valor ao produto.

Também, o Brasil só irá apresentar vantagem competitiva se diversificar a atual oferta de cultivares, colocando no mercado cultivares adaptável a cada região de plantio e investir mais em tecnologias, de modo que os sistemas produtivos consigam agregar maior eficiência técnica e econômica. e investir mais em tecnologias, para que as regiões geográficas tenham estabilidade de produção. 


\section{REFERÊNCIAS}

AGRIANUAL - 1999. Anuário da agricultura brasileira: cebola. São Paulo: FNP Consultoria e Comércio, 1999.

AGRIANUAL - 2002. Anuário da agricultura brasileira: cebola. São Paulo: FNP Consultoria e Comércio, 2002.

AGRIANUAL - 2005. Anuário da agricultura brasileira: cebola. São Paulo: FNP Consultoria e Comércio, 2005.

AGRIANUAL - 2008. Anuário da agricultura brasileira: cebola. São Paulo: FNP Consultoria e Comércio, 2008.

AGRIANUAL - 2009. Anuário da agricultura brasileira: cebola. São Paulo: FNP Consultoria e Comércio, 2009.

CAMARGO, A. Maria M. P. de; CAMARGO, Felipe Pires de.; CAMARCO Filho, Waldemar Pires de. Distribuição geográfica da produção de hortaliças no estado de São Paulo: participação no país, concentração regional e evolução no período 1996-2006. Informações Econômicas, SP, v.38, n.1, p. 28-35, jan. 2008.

CAMARGO, F. P. de; CAMARGO FILHO, W. P. de; ALVES, H.S. Ocorrências no mercado de cebola no Brasil com o MERCOSUL: produção brasileira, importação e preços. Informações Econômicas, SP, v.36, n.7, p. 79-82 jul. 2006.

CAMARGO FILHO, W.P.; ALVES, H.S. Produção de cebola no MERCOSUL: aspectos tecnológicos e integração de mercado no Brasil e Argentina. Informações Econômicas, SP, v.32, n.5, p. 7-17, maio 2005.

CAMARGO FILHO, W.P de C.; MAZZEI, A.R. Mercado de cebola: tendências de produção e de preços no Brasil e na Argentina. Informações Econômicas, São Paulo, v, 31, n.6, p. 51 54, jun. 2001.

CAMARGO FILHO, W.P. Produção e mercado de cebola com o MERCOSUL: 1990-98. Informações Econômicas, São Paulo, v.29, n.4, p.19-30, 1999.

CARDOSO, A. I. I.; COSTA, C. D. da. Produção de bulbinhos de cebola em bandejas de isopor. Scientia Agrícola, Piracicaba, SP, v.56, n.4, p. 969-974, 1999.

IBGE- INSTITUTO BRASILEIRO DE GEOGRAFIA E ESTATÍSTICA. Pesquisa de Orçamentos familiares 2002-2003. 251p. Disponível em http://www.ibge.gov.br/ home/ estatistica/ populacao/condicaodevida/pof/2002aquisicao/ aquisição. Acesso: 23 abril 2009.

IBGE- INSTITUTO BRASILEIRO DE GEOGRAFIA E ESTATÍSTICA. Produção agrícola municipal de cebola. Disponível em: 〈http://www.ibge.gov.br>. Acesso em: 11 dez. 2008a.

IBGE- INSTITUTO BRASILEIRO DE GEOGRAFIA E ESTATÍSTICA. Levantamento sistemático da produção agrícola. Disponível em: <http://www.ibge.gov.br/home/ presidencia/noticias/noticia_visualiza.php?id_noticia=1161\&id_pagina=1>. Acesso em: 18 dez. 2008b. 
REZENDE, J. T. V. de et al. Desempenho produtivo de cultivares de cebola em Guarapuava, Paraná. Ambiência, Guarapuava, PR, v.3, n.2, p.193-199, maio/ago. 2007.

RESENDE, L.M.A.; MASCARENHAS M.H.T.; SIMÃO M.L.R. Panorama da produção e da comercialização da cebola em Minas Gerais. Informe Agropecuário, v.23, n. 218, p. 7-19, 2002.

SOUZA, R.G.; RESENDE, G.M. Cultura da cebola. Lavras: UFLA, 2002, 115 p.

VILELA, N.J. et al. Desafios e oportunidades para o agronegócio da cebola no Brasil. Hortic. Bras., v.23, n.4, p. 1029 - 1033, out - dez. 2005.

VILELA, N. J. et al. Identificação de sistemas de produção de cebola nos principais estados produtores: relatório final de pesquisa. Brasília: Embrapa - Hortaliças, 2002. In: VILELA, N.J.et al. Desafios e oportunidades para o agronegócio da cebola no Brasil. Hortic. Bras., v.23, n.4, p. 1029 - 1033, out - dez. 2005. 